\title{
What is the role of online support from the perspective of facilitators of face-to-face support groups? A multi-method study of the use of breast cancer online communities
}

\author{
Jacqueline L. Bender ${ }^{\mathrm{a}, \mathrm{b}, \mathrm{c}, *}$, Joel Katz ${ }^{\mathrm{e}}$, Lorraine E. Ferris ${ }^{\mathrm{a}}$, Alejandro R. Jadad ${ }^{\mathrm{a}, \mathrm{b}, \mathrm{c}, \mathrm{d}}$ \\ ${ }^{a}$ Dalla Lana School of Public Health, University of Toronto, Toronto, ON, Canada \\ ${ }^{\mathrm{b}}$ Centre for Global eHealth Innovation, University Health Network, Toronto, ON, Canada \\ ${ }^{\mathrm{c}}$ ELLICSR: Centre for Health, Wellness and Cancer Survivorship, University Health Network, Toronto, ON, Canada \\ ${ }^{\mathrm{d}}$ Department of Health Policy, Management and Evaluation, University of Toronto, Toronto, ON, Canada \\ e Department of Psychology, York University, Toronto, ON, Canada
}

\section{A R T I C L E I N F O}

\section{Article history:}

Received 31 October 2012

Received in revised form 2 June 2013

Accepted 8 July 2013

\section{Keywords:}

Breast cancer

Peer support

Online communities

Internet

Supportive care

\begin{abstract}
A B S T R A C T
Objective: To explore the role of online communities from the perspective of breast cancer survivors who are facilitators of face-to-face support groups.

Methods: Seventy-three attendees (73\% response rate) of a Canadian support group-training program completed a questionnaire examining when and why they used online communities. A purposive sample of 12 respondents was interviewed on how they used them in comparison to traditional supportive care. Survey responses were analyzed using descriptive statistics, and interview transcripts using a descriptive interpretive approach.

Results: Online communities were used by $31.5 \%$, mostly during treatment (73.9\%), daily or weekly (91.3\%), primarily for information (91.3\%) and symptom management (69.6\%) and less for emotional support (47.8\%). Reasons for non-use were lack of need (48.0\%), self-efficacy (30.0\%), trust (24.0\%), and awareness (20.0\%). Respondents used online communities to address unmet needs during periods of stress and uncertainty. A multi-theory framework helps to explain the conditions influencing their use. Conclusion: Online communities have the potential to fill gaps in supportive care by addressing the unmet needs of a subgroup of breast cancer survivors. Further research is required among typical cancer survivors.
\end{abstract}

Practice implications: Online communities could play an important role as a supplemental resource for a sub-group of breast cancer survivors.

\section{Introduction}

Peer support groups have shown great promise in meeting the supportive care needs of people with cancer and are considered an important complement to the formal health care system [1-3]. However, practical barriers such as time, mobility and geography limit their use [4]. Online support groups, also known as online communities, have the potential to overcome many of the barriers

\footnotetext{
This work is a component of JLB's PhD thesis at the University of Toronto: Bender JL (2011) The web of care: a multi-method study examining the role of online communities as a source of peer-to-peer supportive care for breast cancer survivors. Dissertation, University of Toronto.

* Corresponding author at: Dalla Lana School of Public Health, University of Toronto, c/o Centre for Global eHealth Innovation, University Health Network, 190 Elizabeth Street, Toronto, ON M5G 2C4, Canada. Tel.: +1 4163404800 ; fax: +1 4163403595 .

E-mail address: jbender@ehealthinnovation.org (J.L. Bender)
}

to in-person support, while reaching a wider segment of the population [5-7]. They provide additional advantages such as 24-h accessibility from the convenience of home, anonymity, similarity of experiences and diversity of resources [8].

Breast cancer support groups ranked third (after chronic fatigue and diabetes) in frequency of postings in an evaluation of disease support groups on the Internet [9]. Although there is limited empirical evidence concerning their impact [7,10], several qualitative studies have shown that such groups provide breast cancer survivors with important benefits. These include: reassurance and hope for the future [11-13]; reduced feelings of isolation and uncertainty [12-15]; validation of concerns not dealt with by health professionals [11]; and enhanced understanding of the disease $[11,13,16]$ and ability to cope [15].

Although breast cancer survivors appear to be one of the more active illness groups online [9], little is known about the proportion who use online communities. A 2010 Pew survey of 3001 U.S. found that Internet users living with one or more chronic 
conditions such as cancer were more likely to report using online communities [17]. Specifically, 37\% read someone else's experience of a health issue on an online group, website or blog compared to $31 \%$ of those reporting no chronic conditions. A hospital-based survey of 679 Dutch patients with breast cancer, rheumatoid arthritis or fibromyalgia published in 2009 found that $15 \%$ of the patients surveyed had used an online community [18].

Similarly, we know little about the individual, social or contextual factors that influence people to seek online support, or how participation in online communities compares to traditional forms of support. According to research by Davison et al. embarrassment, stigma and disfigurement motivate patients to seek both online and offline forms of support, while online support occurs at higher rates for those whose conditions are poorly understood or overlooked by the medical community [9]. A survey of 1039 Japanese breast cancer survivors demonstrated that those who used both online communities and face-to-face support groups received the most benefit [19]. Online communities were used immediately after diagnosis, whereas face-to-face groups were used after beginning or completing treatment, suggesting that they may serve different purposes.

This study focuses on breast cancer survivors who are facilitators of face-to-face support groups. Several studies indicate that the success of support groups is largely dependent on the group leader [20-22]. Our goal was to leverage their expertise in providing support, to better understand the role of online support, including how it compares to face-to-face support, and whether it could complement traditional supportive care services. Hence, the study purpose was twofold: (1) to identify the extent to which this unique sample of breast cancer survivors used online communities including their timing, frequency and reasons for use; and (2) to explore the conditions under which they used online communities, and how they compare to traditional sources of supportive care. Lastly, as the results were being analyzed it became apparent that theories of social support, technology adoption and health behavior could help to explain the study findings. Therefore, we used selected theories to frame the findings.

\section{Methods}

\subsection{Study design}

We used a multi-method study design involving a crosssectional survey followed by qualitative interviews. This study was approved by the University of Toronto Research Ethics Board [23].

\subsection{Participants}

The sample for the survey was drawn from the 2008 and 2009 attendee list of a support group facilitator-training program offered by Willow Breast Cancer Support Canada, a national nonprofit support agency (www.willow.org). This program is attended by breast cancer survivors at least one-year post diagnosis, seeking to enhance their skills as support group facilitators. The survey was restricted to program attendees who had used the Internet to send and receive email; and could read and speak English. A purposive sample [24] of survey respondents who had used an online community was recruited for a follow-up interview. The sample size for the qualitative study was determined by the saturation point of the data [25], which occurred after 12 participants were recruited.

\subsection{Data collection}

Program attendees were notified of the study through a Willow newsletter. One week after the mail-out of the newsletter, each attendee was sent, by postal mail, a survey package (a letter of invitation, questionnaire and a pre-paid postage return envelope). Non-responders were sent up to two follow-up letters (with another survey package). Participants were also given the option to complete and submit the questionnaire online. Survey respondents who answered on their questionnaire that they were willing to be interviewed, were contacted by telephone. Each agreeable participant took part in one 60-90-min semi-structured interview, conducted face-to-face $(n=1)$ or by telephone $(n=11)$ depending on the preference of the participant. The same investigator (JLB) conducted all interviews to ensure consistency and trustworthiness of data collection. Interviews were audio-recorded and fully transcribed.

\subsection{Survey instrument}

The survey requested information on demographic and disease characteristics, use of the Internet, social media and online communities. Socio-demographic characteristics included age, ethnicity, highest level of education completed, total household income and approximate size of town or city of residence. Use of online communities was assessed with the question: "Have you ever visited (e.g. read or posted a message) a breast cancer website that allows you to communicate with other women diagnosed with breast cancer, such as an online discussion forum or chat room?" Individuals who responded 'no' were asked to indicate from a list, the reasons they had not used an online community for breast cancer related purposes. Users of breast cancer online communities were asked to indicate how they had used them, when they most frequently used them, and the reasons they used them (selected from a list). The survey was pilot-tested with seven of Willow's staff members.

\subsection{Interview guide}

Interview participants were asked to talk about how they became aware of online communities; what motivated them to seek support from an online community; what was going on in their lives when they used them; what motivated them to continue or stop using them; how, in their opinion, online communities compared to traditional sources of supportive care; and what role they played for them personally. Clarification probes and follow-up questions were used to explore issues in greater depth and to verify understanding of the information being collected [26].

\subsection{Data analysis}

Survey data was analyzed using the statistical software package SPSS version 17 (IBM Corporation, Somers, NY, USA). Descriptive statistics were used to describe respondent characteristics, Internet, social media and online community use. Transcribed interviews were analyzed using a qualitative descriptive interpretive approach combining thematic content analysis [26] and constant comparison methods [27] facilitated by QSR NVIVO 8.0 data management software. Transcripts were coded in an iterative manner using codes derived from the data. A second team member coded three randomly selected transcripts, resulting in minor modifications to the coding scheme. The coded data was rearranged with accompanying text into comparative tables to contrast the participants' views and experiences, and identify common themes. Social comparison theory [28], Transactional Model of Stress and Coping [29], Technology Acceptance Model [30], and the Theory of Planned Behavior [31] were used to frame the findings. 


\section{Results}

\subsection{Survey}

\subsubsection{Survey respondents}

In total, 73 of the 100 individuals surveyed returned a completed questionnaire ( 6 of these did so online). All were active members of a face-to-face support group, 68 were lead facilitators and five were facilitators-in-training. Table 1 summarizes respondent characteristics.

\subsubsection{Prevalence and type of online support use}

As shown in Table 2, 31.5\% reported having used an online breast cancer community and $17.8 \%$ reported using Facebook to communicate with other breast cancer survivors. From a list of 20 online breast cancer communities, users reported using a median of 4 (IQR 4.2). The top ten online communities that respondents reported using are shown in Table 3.

\subsubsection{Timing and frequency of use}

Users reported using online communities most frequently during treatment (73.9\%) (Table 2). During this peak use period, nearly all respondents (91.3\%) reported using online communities on a daily or weekly basis. At the time of the survey, most (72.7\%) reported using online communities once per month or less.

\subsubsection{Reasons for use}

The top three reasons reported for using online breast cancer communities were to address informational or symptom management needs (Table 4). The main reasons for not using online breast cancer communities related to lack of perceived need, trust, selfefficacy and awareness (Table 5).

\subsection{Qualitative interviews}

\subsubsection{Interview participants}

Interview participants were similar in characteristics to survey respondents based on comparative statistics, which found no
Table 2

Prevalence, timing and frequency of use.

\begin{tabular}{|c|c|}
\hline Characteristic & $n(\%)$ \\
\hline \multicolumn{2}{|l|}{ Frequency of general internet use $(N=73)$} \\
\hline At least once a day & $53(72.6)$ \\
\hline At least once a week & $16(21.9)$ \\
\hline At least once a month & $1(1.4)$ \\
\hline Less than once a month & $3(4.1)$ \\
\hline $\begin{array}{l}\text { Use of Internet to search for information about } \\
\text { breast cancer }(N=73)\end{array}$ & $65(89.0)$ \\
\hline Use of Facebook $(N=73)$ & $32(43.8)$ \\
\hline $\begin{array}{l}\text { Use of Facebook to communicate with breast } \\
\text { cancer survivors }(N=32)\end{array}$ & $13(40.6)$ \\
\hline Use of an online breast cancer (b.c.) & $23(31.5)$ \\
\hline \multicolumn{2}{|l|}{ community $(N=73)$} \\
\hline Posted content in an online b.c. community $(N=23)$ & $13(59.1)$ \\
\hline \multicolumn{2}{|l|}{ Period of most frequent online b.c. } \\
\hline \multicolumn{2}{|l|}{ community use $(N=23)$} \\
\hline During diagnostic testing & $5(21.7)$ \\
\hline After diagnosis but before treatment & $12(52.2)$ \\
\hline During treatment & $17(73.9)$ \\
\hline After treatment, but while on hormone therapy & $14(60.9)$ \\
\hline After all treatment & $11(47.8)$ \\
\hline \multicolumn{2}{|l|}{$\begin{array}{l}\text { Frequency of use during peak online b.c. } \\
\text { community use }(N=23)\end{array}$} \\
\hline At least once a day & $9(39.1)$ \\
\hline At least once a week & $12(52.2)$ \\
\hline At least once a month & $2(8.7)$ \\
\hline Less than once a month & $0(0.0)$ \\
\hline \multicolumn{2}{|l|}{$\begin{array}{l}\text { Frequency of online b.c. community use in the } \\
\text { last } 3 \text { months }(N=22)\end{array}$} \\
\hline At least once a day & $2(9.1)$ \\
\hline At least once a week & $4(18.2)$ \\
\hline At least once a month & $6(27.3)$ \\
\hline Less than once a month & $10(45.5)$ \\
\hline
\end{tabular}

b.c., breast cancer.

significant differences (Table 1). In addition, seven reported having less common conditions (e.g. BRCA gene mutation, triple negative or inflammatory breast cancer, or co-morbidities). The majority did not consider themselves experienced computer users.

Table 1

Characteristics of survey and interview respondents.

\begin{tabular}{|c|c|c|}
\hline Characteristic $^{\mathrm{a}}$ & Survey respondents $N=73$ & Interview participants $N=12$ \\
\hline Age in years, mean $(\mathrm{SD})(N=70)$ & $56(9.52)$ & $56.2(8.71)$ \\
\hline \multicolumn{3}{|l|}{ Place of birth, $n(\%)(N=73)$} \\
\hline Canada & $64(87.7)$ & $11(91.2)$ \\
\hline \multicolumn{3}{|l|}{ Ethnicity, $n(\%)(n=73)$} \\
\hline White & $71(97.3)$ & $12(100)$ \\
\hline \multicolumn{3}{|l|}{ Relationship status, $n(\%)(N=73)$} \\
\hline Single, divorced, or widowed & $14(19.2)$ & $2(16.7)$ \\
\hline Married or in a relationship & $59(80.8)$ & $10(83.3)$ \\
\hline \multicolumn{3}{|l|}{ Education, $n(\%)(N=70)$} \\
\hline Secondary school or less & $13(18.3)$ & $0(0)$ \\
\hline College or technical school & $33(46.5)$ & $6(50.0)$ \\
\hline University & $24(35.2)$ & $6(50.0)$ \\
\hline \multicolumn{3}{|l|}{ Total household income, $n(\%)(N=64)$} \\
\hline Less than $\$ 40,000$ & $18(28.1)$ & $4(33.3)$ \\
\hline$\$ 40,001$ to $\$ 80,000$ & $28(43.8)$ & $4(33.3)$ \\
\hline$\$ 80,001+$ & $18(28.1)$ & $4(33.3)$ \\
\hline \multicolumn{3}{|l|}{ City size, $n(\%)(N=73)$} \\
\hline Fewer than 10,000 people & $27(37.0)$ & $4(33.3)$ \\
\hline 10,001-99,999 people & $32(43.8)$ & $5(41.7)$ \\
\hline 100,000 or more people & $14(19.2)$ & $3(35.0)$ \\
\hline Years since diagnosis, median (IQR) $(N=73)$ & $5.92(7.3)$ & $3.37(5.7)$ \\
\hline Recurrence, $n(\%)(N=73)$ & $12(16.4)$ & $1(8.3)$ \\
\hline \multicolumn{3}{|l|}{ Treatment status, $n(\%)(N=72)$} \\
\hline Undergoing treatment & $3(4.2)$ & $1(8.3)$ \\
\hline Completed, but on HRT & $32(44.4)$ & $5(41.7)$ \\
\hline Completed all treatment & $36(51.4)$ & $4(33.3)$ \\
\hline Investigating possible recurrence & $0(0)$ & $2(16.7)$ \\
\hline
\end{tabular}

\footnotetext{
${ }^{a}$ Comparative statistics found no significant differences between groups.
} 
Table 3

Top ten online communities ever used by survey respondents $(N=23)$.

\begin{tabular}{clr}
\hline Rank & Online breast cancer community ${ }^{\text {a }}$ & $n(\%)$ \\
\hline 1 & Breastcancer.org (www.breastcancer.org) & $18(81.8)$ \\
2 & Willow Breast Cancer Support Canada (www.willow.org) & $17(77.3)$ \\
3 & Breast Cancer Action Nova Scotia (www.bca.ns.ca) - CLOSED & $9(40.9)$ \\
4 & Caring Voices (www.caringvoices.ca) (BEING REDESIGNED) & $7(31.8)$ \\
5 & Living Beyond Breast Cancer (www.lbbc.org) & $7(31.8)$ \\
6 & Canadian Breast Cancer Forum (www.breastcancerforum.ca) & $7(31.8)$ \\
7 & (CLOSED) & $5(22.7)$ \\
8 & Breast Cancer Awareness (www.breastcancerawareness.com) & $5(22.7)$ \\
9 & Breast Cancer Now What (www.breastcancernowwhat.ca) & $4(18.2)$ \\
10 & (CLOSED) & $4(18.2)$ \\
\hline
\end{tabular}

a More than one option could be selected.

\subsubsection{Factors that influenced first time use}

Most interview participants $(n=7)$ discovered online communities accidentally, while searching for information to address a specific need. Most $(n=7)$ had not used an online community for any reason prior to being diagnosed with breast cancer, and those who had, did so for work or leisure, but not for personal health reasons. A couple of participants reported having difficulty setting up an account or posting a message, but the majority described online communities as easy-to-use. Some described being apprehensive about posting a message. As one woman explained: "There is a certain amount of trust you just have to throw out there and hope that these are good people". Receiving a supportive response from another community member motivated them to post again.

Some learned about online breast cancer communities through an unsolicited recommendation from a family member, fellow breast cancer survivor, or support group member. Respondents mentioned that women in their support groups often discussed information found in online communities, and that was often how others became aware of these online resources, as well as how to use them. One person was referred to an online community by a health professional. Several participants had the impression that physicians were not supportive of online communities; some had been told by their physicians not to trust them. The perceived negative physician view did not deter these women from using online communities.

\subsubsection{Extent and context of use in relation to other sources of supportive care}

The interviews revealed that participants turned to online communities to address an unmet need, in many cases during periods of peak stress or uncertainty because of an uncommon condition, insufficient support locally or information from health professionals. Many explained that were dissatisfied with the quality of information provided to them by their physicians, and

\section{Table 4}

Reasons for using online communities ${ }^{\mathrm{a}}(N=23)$.

\begin{tabular}{lr}
\hline Reason & $N(\%)$ \\
\hline 1. To obtain information about breast cancer or its treatment & $21(91.3)$ \\
2. To learn how to manage symptoms and side effects & $16(69.6)$ \\
3. To obtain emotional support & $11(47.8)$ \\
4. To prepare for a medical appointment & $10(43.5)$ \\
5. To help others & $9(39.1)$ \\
6. To address fears & $8(34.8)$ \\
7. To address feelings of depression & $7(30.4)$ \\
8. To follow-up on a medical appointment & $6(26.1)$ \\
9. To address feelings of anxiety & $5(21.7)$ \\
10. To address feelings of loneliness & $5(21.7)$ \\
11. To address spiritual concerns & $1(4.3 \%)$ \\
\hline
\end{tabular}

a More than one option could be selected.
Table 5

Reasons for not using online communities ${ }^{\mathrm{a}}(N=50)$.

\begin{tabular}{ll}
\hline Reason & $N(\%)$ \\
\hline 1. Needs met by offline peer support network & $24(48.0 \%)$ \\
2. Not confident using online communities & $15(30.0 \%)$ \\
3. Did not trust Internet security & $12(24.0 \%)$ \\
4. Did not trust information from the Internet & $12(24.0 \%)$ \\
5. Not confident using computers in general & $10(20.0 \%)$ \\
6. Never heard of online communities & $10(20.0 \%)$ \\
\hline
\end{tabular}

a More than one option could be selected.

considered face-to-face groups to be reserved for "emotional stuff". Three typical use case scenarios are depicted in Table 6. Participants who considered online communities to be a major resource all had uncommon conditions and had found an online community that met their specific needs.

Participants described seeking help from online communities primarily for two specific reasons to: prepare for or decide on a course of treatment; or, manage or cope with symptoms and adverse effects. Several participants felt that there was a lack of attention paid to these issues and did not regard their physicians as the best source of information on these topics. Participants explained that they were seeking help to understand "what to expect", and reassurance that theirs was a typical or normal experience. Once participants' needs were met, many stopped using the online community. The main factors that motivated use post-treatment were the experience of a new or worsening symptom, the need for subsequent treatment, and a desire to stay informed or help others. Nearly all participants described reaching a point at which they wanted to move beyond cancer, and this included distancing themselves from their online community.

\subsubsection{Role in relation to other sources of supportive care}

As shown in Table 7, online communities seemed to play a distinct role in comparison to traditional sources of supportive care. Many participants recommended online communities to their face-to-face support groups as a supplemental resource. One woman described using online communities to answer questions raised in her support group. As one woman described:

"It's a fabulous, incredible website with incredible support. In fact I think I was bragging to my doctor about that website. To him he thought it was ridiculous and, um, I was telling him 'you have no idea the support systems that women have' ... any question I had was answered, any fear I had was reassured, um and I didn't have to seek out as much help."

However, online communities were not without their limitations. Participants explained that they felt more emotionally connected to women in their support groups; that not all communication in online communities was supportive and when it was not, it led to misunderstandings; and that a lack of computer skills would likely prevent others from using online communities.

\subsubsection{Not one in the same}

Online communities were also not seen as being equal. Several participants described testing out a number of online communities before they found one that suited them. Reasons for leaving an online community included a lack of personally relevant information (e.g. not focused on advanced cancer), not receiving a timely response, and a need to avoid anxiety-provoking details about cancer (e.g. participants doing poorly). Nearly all participants indicated that they would be uncomfortable discussing breast cancer related issues on Facebook because of its perceived popularity and lack of privacy. Breast cancer specific online communities were perceived as more trustworthy based on the 
Table 6

Use case scenarios.

\begin{tabular}{|c|c|c|}
\hline Source $(n)$ & Description & Quote \\
\hline Major (5) & $\begin{array}{l}\text { For participant F201, online communities became a major source } \\
\text { of support because she had an existing condition that put her at } \\
\text { greater health risk from breast cancer treatment, her treatment } \\
\text { course was not straight-forward and she could not find anyone } \\
\text { locally who shared her particular experience or condition. }\end{array}$ & $\begin{array}{l}\text { "It was just such wonderful support for me at the beginning when I } \\
\text { was wondering about whether I should even have the surgery or if } \\
\text { I should go on the chemo route, um you know there was dispute } \\
\text { about that because I had [disease] and a lot of the things that are } \\
\text { recommended would probably kill me... You know as time went } \\
\text { on I needed that less. But when I needed it badly I had it." }\end{array}$ \\
\hline Gap-filler (4) & $\begin{array}{l}\text { For participant F108, online communities were an important } \\
\text { resource when she lacked access to local information or support. } \\
\text { However, } \\
\text { once she was introduced to sources of face-to-face support locally } \\
\text { through a new treatment center, she used online communities less } \\
\text { often. }\end{array}$ & $\begin{array}{l}\text { "I'd say about forty percent. I think um being actually at the clinic } \\
\text { and talking with other patients was most helpful... and the } \\
\text { women in the car pool... and the counselor in the clinic... I found } \\
\text { that once I started that connection [with a new treatment center] I } \\
\text { would go online but not as often." }\end{array}$ \\
\hline Minor (3) & $\begin{array}{l}\text { For participant F75, online communities were a minor source of } \\
\text { support. They functioned to meet her needs in times of stress and } \\
\text { uncertainty. In particular, she spoke extensively about the benefit } \\
\text { and importance of being able to obtain an immediate response to } \\
\text { an urgent need from online communities. }\end{array}$ & $\begin{array}{l}\text { "I would say that only small piece of support that I got was } \\
\text { through online social networking. The pattern would be around } \\
\text { treatments that affected my appearance like losing my hair or } \\
\text { having a mastectomy, that were very anxiety provoking } \\
\text { experiences." }\end{array}$ \\
\hline
\end{tabular}

quality, currency and empathic nature of the postings that they contained, and the belief that people who used them were likely to do so for genuine reasons. Face-to-face support groups and less anonymous online resources such as Facebook were perceived as affording participants less control over their interaction with others, including when they choose to disclose personal information and with whom.

\section{Discussion and conclusion}

\subsection{Discussion}

The prevalence of health-related online community use found in this sample is similar to that reported in a survey of adult Internet users in the United States in 2011 [17]. But it is about $10 \%$ greater than that reported in a sample of Dutch patients (that included breast cancer patients) conducted a year earlier [18]. This may be because of the unique characteristics of the sample. Support group facilitators are not necessarily typical of breast cancer survivors. Previous research suggests that they may be better educated, better adjusted, and include fewer minority groups [32]. These trends were reflected in the present sample, which was nearly all white, and college or universityeducated. In addition, pre-existing personality factors may have influenced them to use the Internet for peer support. However, it is unlikely, that being associated with a support agency influenced them to use online communities, given that the majority of survey respondents reported using them during treatment, which would have been before they attended a facilitator-training workshop.

Table 7

Benefits of online communities in relation to traditional sources of supportive care

\begin{tabular}{|c|c|c|}
\hline Benefit & Comparison & Quote \\
\hline Richness of information & $\begin{array}{l}\text { The information in online communities was described as more } \\
\text { detailed, relevant and practical compared to the information they } \\
\text { obtained from face-to-face support groups and health } \\
\text { professionals, which was described as insufficient and lacking } \\
\text { detail. }\end{array}$ & $\begin{array}{l}\text { "It's a different kind of information. It's more supportive and } \\
\text { personalized. Doctor's don't tell you everything, and support } \\
\text { groups are about the emotional stuff." }\end{array}$ \\
\hline Reassurance from similar others & $\begin{array}{l}\text { Compared to face-to-face support, online communities were } \\
\text { described as a more effective means to find other women with } \\
\text { similar experiences, particularly for those with less common } \\
\text { conditions. They were also described as a more effective way to } \\
\text { obtain reassurance from women who had been through it and } \\
\text { were on the other end of it, without have to explicitly ask for }\end{array}$ & $\begin{array}{l}\text { "A lot of the time you've got very panicky women that are on these } \\
\text { sites and the older ones who might have been at it for a few } \\
\text { months reassure them. So in a way I was being reassured even } \\
\text { though they weren't talking to me but they were talking to people } \\
\text { who were like me so that's why I never really needed to post or to } \\
\text { tell my story personally because it was easy to find me." }\end{array}$ \\
\hline
\end{tabular}

Availability

Anonymity

Low commitment support.

Participants commented on how useful it was to have a resource that they could use to address their needs when they most urgently needed it, as opposed to when or where it was convenient for someone else to provide it. Participants explained that support groups usually meet once per month, and it takes time to obtain an appointment with a physician, whereas one could get an answer from an online community immediately.

Online communities were described as safe fora to discuss topics that were difficult to discuss in support groups or with health professionals (e.g. nasty side effects, sexuality and death). Participants explained that online communities compared to faceto-face support groups afforded them more control over how others viewed or treated them.

Online communities offered a less emotionally demanding and low commitment form of support, compared to face-to-face support groups and less anonymous online resources such as Facebook, which were perceived as affording less control over interactions. It was explained that although one did not have to a return to a face-to-face group, members of the group would likely try to encourage that person to return.
“It's so accessible. If you have to book an appointment with someone and you can't deal with it when you're ready to deal with it you know what ... I mean you have to wait ... by going online it can be immediate."

"This was safe ... there was nobody going to get back to me if I didn't want them to and I could be fully open and not worry about the consequences."

"Like the thing about going on a chat group is that I can get in, I can get out ... there is no larger commitment. Other than me going online and typing a few sentences and if I don't want to do it anymore, I just leave. And nobody is going to keep emailing me or contacting me." 
Like previous studies with more typical cancer survivors $[33,34]$, participants in our sample turned to online communities primarily for information, and less so for emotional support. Our study supports previous research describing the main advantages and disadvantages of the Internet as a communication tool [8,11,12,35-37]. Our study extends the work of others by uncovering the reasons for not using online communities. Beyond a lack of perceived need reported by nearly $50 \%$ of respondents, these included a lack of confidence using online communities (30\%), trust in Internet resources (24\%), confidence using computers in general (20\%), or awareness of online breast cancer communities (20\%). These findings reflect many of the modifiable factors that have been shown to influence Internet use for health information more generally (e.g., a positive outcome expectancy, previous use of health websites, positive Internet self-efficacy) [38].

Perhaps most importantly, this study has identified reasons (unmet needs), circumstances (treatment, symptoms, uncommon condition, insufficient local support or information from health professionals) and conditions (stress and uncertainty) that may influence a sub-group of breast cancer survivors to use online communities. The treatment phase is characterized by uncertainty, and information and symptom management needs $[39,40]$. Health-care induced anxiety is more likely to influence patients to seek peer support, compared to personal characteristics or social circumstances [9]. Breast cancer survivors who experience significant anxiety or depression report two to three times as many unmet supportive care needs [41]. Studies involving more typical breast cancer survivors have demonstrated that online communities can reduce anxiety [42], and that use is contingent on needs $[43,44]$.

Our study also provides preliminary evidence of the potential of online communities to complement traditional sources of supportive care, as proposed by others [7]. Compared to support from face-to-face groups or a health professional, online communities seemed to play a distinct and supplemental role because of their quality of information, reassurance from similar others, availability and immediacy of a response, relative anonymity, control over interpersonal consequences of their illness, low commitment and expected reciprocity. However, online communities were not regarded equally or considered universally beneficial - findings that suggest patients may need to self-select online communities to obtain optimal benefits. Future efforts should focus on identifying factors that determine their effectiveness and for whom.

We propose that Social Comparison Theory [28], Transactional Theory of Stress and Coping Theory [29], and a decomposed version of the combined Technology Acceptance Model and Theory of Planned Behavior [45] with the addition of perceived trust [46] could help explain the individual and contextual factors that influence breast cancer survivors to use online communities. Although previous studies have used stress and coping theories to explain the effects of online communities among breast cancer survivors $[9,33,35,47,48]$, and technology adoption theories to explain intentions to use non-health related online communities [46], no known studies have used these theoretical perspectives in combination for this purpose. Table 8 lists principles and constructs from these theories and the corresponding results.

\subsubsection{Social comparison theory (SCT)}

SCT asserts that under conditions of threat and uncertainty, people seek similar others to compare the appropriateness of their thoughts, feelings or behaviors [28]. Previous research has demonstrated that cancer patients prefer to make upward comparisons with others who have overcome threatening circumstances or adjusted well to them, avoiding those who are doing poorly [49]. Our study supports these conclusions. Interview participants reported looking for practical information and reassurance from women who "had been through it and were on the other end of it". Reading stories of women who were worse off influenced some participants to withdraw from an online community, as has been reported by others [44].

\subsubsection{Transactional theory of stress and coping theory (TTSCT)}

TTSCT suggests that support from peers can promote coping efforts and lessen negative appraisals of events, which in turn reduce or buffer anxiety [29]. Participants mainly used online communities to obtain information and make upward comparisons during periods of stress and uncertainty, suggestive of problem-focused coping. Similar conclusions have been drawn in studies involving more typical breast cancer survivors. A content analysis of 10 cancer mailing lists revealed numerous examples of

Table 8

Theoretical and practical interpretation of findings.

\begin{tabular}{|c|c|c|}
\hline Theory & Theory component & Study results \\
\hline Social comparison theory & Upward comparisons & $\begin{array}{l}\text {-To find others who share specific experiences or } \\
\text { disease characteristics that are doing well } \\
\text {-To limit exposure to those doing poorly }\end{array}$ \\
\hline Transactional model of stress and coping & Problem-focused coping & $\begin{array}{l}\text {-To obtain practical answers to specific questions } \\
\text {-To reduce uncertainty and anxiety }\end{array}$ \\
\hline $\begin{array}{l}\text { Technology acceptance model/Theory } \\
\text { of planned behavior (TAM/TPB) }\end{array}$ & Attitude: perceived usefulness & $\begin{array}{l}\text {-To address unmet needs } \\
\text {-To obtain timely, supportive responses } \\
\text {-To obtain reassurance from others who share specific experiences } \\
\text { or disease characteristics that are doing well }\end{array}$ \\
\hline TAM/TPB & Attitude: perceived ease of use & $\begin{array}{l}\text {-Easy to log-on and set up an account } \\
\text {-Easy to navigate and find specific information } \\
\text {-Easy to post a comment and view the response }\end{array}$ \\
\hline TAM/TPB & Attitude: perceived trust & $\begin{array}{l}\text {-To find well written, accurate and current messages } \\
\text {-To receive empathic and supportive responses } \\
\text {-To be reassured of the credibility of the site owner } \\
\text {-To protect privacy and confidentiality }\end{array}$ \\
\hline TAM/TPB & Subjective norms & $\begin{array}{l}\text {-Opinions of relevant others (e.g., survivors) regarding their usefulness } \\
\text {-Opinions of relevant others (e.g., survivors) regarding its credibility }\end{array}$ \\
\hline TAM/TPB & Behavioral control & $\begin{array}{l}\text {-Perceived ability to identify credible information online } \\
\text {-Verbal persuasion from other cancer survivors } \\
\text {-Guidance from other cancer survivors on how to use an online community } \\
\text {-Opportunities to observe how other cancer survivors use online communities }\end{array}$ \\
\hline
\end{tabular}


active coping behaviors, and encouragement from other community members to employ active coping strategies [33]. Similarly, a survey with users and non-users of cancer online communities, demonstrated that cognitive avoidance, a form of passive coping was associated with non-use [33]. Seeking information is also considered a form of cognitive control and means to gain mastery over an event [29]. Coping strategies that enhance perceptions of control are an important element in the process of adjustment to cancer [50]. The availability, anonymity and low commitment afforded by the medium also served to enhance participants' sense of control over their situations, further distinguishing it as a unique supportive care resource.

\subsubsection{Technology acceptance model (TAM)}

The TAM asserts that attitudes toward using IT systems are determined by their perceived usefulness and perceived ease of use [30]. The main reasons for not using online communities identified in this study are consistent with the TAM (e.g. lack of perceived need and confidence). Interestingly, a perceived lack of computer skills did not seem to represent a barrier for most of those who reported using online communities. The usefulness of the online community was more important than it's perceived ease-of-use. Similarly, Sandaunet [44] reported that breast cancer survivors' use of online support groups was contingent on their needs and was not influenced or limited by their perceived lack of Internet experience.

\subsubsection{Theory of planned behavior (TPB)}

The TPB maintains that intentions to perform a health behavior are influenced by (1) attitudes toward performing the behavior, (2) subjective norms associated with the behavior and (3) behavioral control to perform the behavior [31]. Lin [46] tested the application of a combined TAM/TPB model to explain the use of generalpurpose online communities, and found that attitude (decomposed as perceived usefulness, ease of use and trust) and perceived behavioral control were significant predictors of intention, while subjective norms were not. Our study suggests that each of these factors is important. The perceived usefulness of an online community was judged in part based on its perceived trustworthiness, as well as recommendations from trusted peers. Non-users reported not having sufficient confidence to use online communities, while users perceived themselves as capable or described incidents that would have facilitated the development of selfefficacy to use online communities vicariously.

Not all of the results from the study could be fully explained using the principles and constructs from the selected theories, and not all of the factors from the theories were represented in the discussion. However, none of the theories could alone account for all of the findings discussed, suggesting that a multi-theory perspective may be helpful in understanding the use of online communities by patients. Other researchers have concluded that multiple theories are required to understand the adoption of health technology systems by clinicians in clinical work environments [51]. There are also other potentially applicable theories that warrant attention. An example of which is the Uses and Gratification Theory of mass communication, which asserts that users are goal oriented in their media use and they seek media that best fulfills their needs [52].

\subsubsection{Limitations}

Support group facilitators and people who have actively sought support from a local agency are not necessarily typical of breast cancer survivors. Their experiences likely differ from those who want peer support but do not know where to find it, or who do not seek it out for whatever reason, or who wish to be peer support providers but do not seek out the experience or opportunity. Lastly, this study was conducted retrospectively and is prone to recall bias. Although, most users were using online communities at the time of the study, a majority reported using online communities more frequently around treatment, which would have been five years prior to their participation in this study. However, as Rozmovits et al. [53] explain, "What people remember and how they remember it provides important and useful information about how they experienced illness and healthcare."

\subsection{Conclusions}

Online communities have the potential to fill gaps in supportive care services by addressing the unmet needs of a sub-group of breast cancer survivors. A multi-theory framework may be required to understand the factors that influence cancer survivors to use online communities as supportive care resources. Further research is required to validate these findings among typical cancer survivors.

\subsection{Practice implications}

Online communities could play an important role as a supplemental supportive care resource for a sub-group of breast cancer survivors.

\section{Funding}

This work was supported by CIHR Strategic Doctoral Fellowships in Health Care, Technology and Place, and Cell Signaling in Mucosal Inflammation and Pain. Dr. Jadad, who is a mentor in both of these programs, was supported by the Canada Research Chair in eHealth Innovation and the University Health Network.

\section{Conflicts of interest}

None.

\section{Acknowledgements}

This work is derived from JLB's PhD thesis at the University of Toronto. JLB is grateful to the support of Hans $\mathrm{Oh}$ in his role as the second coder of the interview transcripts. JLB wishes to acknowledge the guidance of her $\mathrm{PhD}$ thesis committee who are coauthors.

\section{References}

[1] Gottlieb BH, Wachala ED. Cancer support groups: a critical review of empirical studies. Psycho-Oncol 2007;16:379-400.

[2] Hoey LM, Ieropoli SC, White VM, Jefford M. Systematic review of peer-support programs for people with cancer. Patient Educ Couns 2008;70:315-37.

[3] Campbell HS, Phaneuf MR, Deane K. Cancer peer support programs: do they work? Patient Educ Couns 2004;55:3-15.

[4] Owen JE, Internet support and information for women with breast cancer (Doctoral Dissertation). University of Alabama, Birmingham, AL; 2003.

[5] Griffiths F, Lindenmeyer A, Powell J, Lowe P, Thorogood M. Why are health care interventions delivered over the internet? A systematic review of the published literature. J Med Internet Res 2006;8:e10

[6] Strecher V. Internet methods for delivering behavioral and health-related interventions (eHealth). Annu Rev Clin Psychol 2007;3:53-76.

[7] Ziebland S, Wyke S. Health and illness in a connected world: how might sharing experiences on the internet affect people's health? Milbank Quart 2012;90:219-49.

[8] Wright K. Perceptions of online support providers: an examination of perceived homophily. Commun Quart 2000;48:44-59.

[9] Davison KP, Pennebaker JW, Dickerson SS. Who talks? The social psychology of illness support groups. Am Psychol 2000;55:205-17.

[10] Eysenbach G, Powell J, Englesakis M, Rizo C, Stern A. Health related virtual communities and electronic support groups: systematic review of the effects of online peer to peer interactions. Br Med J 2004;328:1166.

[11] Sharf BF. Communicating breast cancer on-line: support and empowerment on the Internet. Women Health 1997;26:65-84. 
[12] Shaw B, McTavish F, Hawkins R, Gustafson DH, Pingree S. Experiences of women with breast cancer: exchanging support over the CHESS network. J Health Commun 2000;5:135-59.

[13] Vilhauer RP. A qualitative study of the experiences of women with metastatic breast cancer. Palliative Support Care 2008;6:249-58.

[14] van Uden-Kraan CF, Drossaert CH, Taal E, Shaw BR, Seydel ER, van de Laar MA. Empowering processes and outcomes of participation in online support groups for patients with breast cancer, arthritis, or fibromyalgia. Qual Health Res 2008;18:405-17.

[15] Rogers S, Chen Q. Internet community group participation: psychosocial benefits for women with breast cancer. J Comput-Mediat Commun 2005;10. article 1.

[16] Hoybye MT, Johansen C, Tjornhoj-Thomsen T. Online interaction. Effects of storytelling in an internet breast cancer support group. Psycho-Oncol 2005; 14:211-20.

[17] Fox S. Social life of health information. Pew Internet and American Life Project May 12; 2011, Retrieved from: http://pewinternet.org/Reports/2011/SocialLife-of-Health-Info.aspx [15.06.12].

[18] van Uden-Kraan CF, Drossaert CH, Taal E, Smit WH, Moens HJ, Siesling S, et al. Health-related Internet use by patients with somatic diseases: frequency of use and characteristics of users. Inform Health Soc Care 2009;34:18-29.

[19] Setoyama Y, Yamazaki Y, Nakayama K. Comparing support to breast cancer patients fro online communities and face-to-face support groups. Patient Educ Couns 2011;85:e95-100

[20] Butow P, Ussher J, Kirsten L, Hobbs KM, Smith K, Wain G, et al. Sustaining leaders of cancer support groups: the role, needs, and difficulties of leaders. Soc Work Health Care 2005;42:39-55.

[21] Butow P, Kirsten L, Ussher J, Wain G, Sandoval M, Hobbs KM, et al. What is the ideal support group? Views of Australian people with cancer and their carers. Psycho-Oncol 2007;16:1039-45.

[22] Owen JE, Bantum EO, Golant M. Benefits and challenges experienced by professional facilitators of online support groups for cancer survivors. Psycho-Oncol 2009;18:144-55.

[23] Bender JL. The web of support: a multi-method study examining the role of online communities as a source or peer-to-peer supportive care for breast cancer survivors (Doctoral dissertation). University of Toronto, Toronto, ON; 2011.

[24] Patton MQ. Qualitative research and evaluation methods. Thousand Oaks, CA: Sage Publications; 2002.

[25] Lincoln YS, Guba EG. Naturalistic inquiry. Thousand Oaks, CA: Sage Publications; 1985

[26] Graneheim UH, Lundman B. Qualitative content analysis in nursing research: concepts, procedures and measures to achieve trustworthiness. Nurse Educ 2004; $24: 105-12$

[27] Miles MB, Huberman AM. Qualitative data analysis: an expanded sourcebook. second ed. Thousand Oaks, CA: Sage Publications; 1994.

[28] Festinger L. A theory of social comparison processed. Hum Relat 1954;7:117-40.

[29] Lazarus RS, Folkman S. Stress, appriasial and coping. New York, NY: Springer; 1984.

[30] Davis FD. Perceived usefulness, perceived ease of use, and user acceptance of information technology. Manag Informat Sci Quart 1989;13:319-39.

[31] Ajzen I. The theory of planned behavior. Organ Behav Hum Dec Proc 1991;50:179-211.

[32] Matthews BA, Baker F, Hann DM, Denniston M, Smith TG. Health status and life satisfaction among breast cancer survivor peer support volunteers. PsychoOncol 2002:11:199-211.
[33] Meier A, Lyons EJ, Frydman G, Forlenza M, Rimer BK. How cancer survivors provide support on cancer-related Internet mailing lists. J Med Internet Res 2007;9:e12.

[34] Rimer BK, Lyons EJ, Ribisl KM, Bowling JM, Golin CE, Forlenza MJ, et al. How new subscribers use cancer-related online mailing lists. J Med Internet Res 2005; 7:e32.

[35] Wright K. Social support within an online cancer community: an assessment of emotional support, perceptions of advantages and disadvantage, and motives for using the community from a communication perspective. J Applied Comm Res 2002;30:195-9.

[36] Wright K, Bell SB. Health-related support groups on the Internet: linking empirical findings to social support and computer-mediated communication theory. J Health Psychol 2003:8:39-54.

[37] Rozmovits L, Ziebland S. What do patients with prostate or breast cancer want from an Internet site? A qualitative study of information needs. Patient Educ Couns 2004;53:57-64.

[38] Mead N, Varnam R, Rogers A, Roland M. What predicts patients' interest in the Internet as a health resource in primary care in England? J Health Serv Res Policy 2003;8:33-9.

[39] Mullan F. Seasons of survival: reflections of a physician with cancer. N Engl J Med 1985;313:270-3.

[40] Fitch MI. Supportive care for cancer patients. Hosp Q 2000;3:39-46.

[41] Hodgkinson K, Butow P, Hunt GE, Pendlebury S, Hobbs KM, Wain G. Breast cancer survivors' supportive care needs $2-10$ years after diagnosis. Support Care Cancer 2007; 15:515-23.

[42] Lieberman M, Goldstein B. Self-help on-line: an outcome evaluation of breast cancer bulletin boards. J Health Psychol 2005;10:855-62.

[43] Lee SY, Hawkins R. Why do patients seek an alternative channel? The effects of unmet needs on patients' health-related Internet use. J Health Commun 2010;15:152-66.

[44] Sandaunet AG. The challenge of fitting in: non-participation and withdrawal from an online self-help group for breast cancer patients. Sociol Health Illness 2008;30:131-44.

[45] Taylor S, Todd PA. Assessing IT usage: a test of competing models. Inform Syst Res 1995;6:144-76.

[46] Lin HF. Understanding behavioral intention to participate in virtual communities. Cyberpsychol Behav 2006:9:540-7.

[47] Gustafson D, Hawkins R, Pingree S, McTavish F, Arora NK, Mendenhall J, et al. Effect of a computer support on younger women with breast cancer. J Gen Intern Med 2001;16:435-45.

[48] Winzelberg AJ, Classen C, Alpers GW, Roberts H, Koopman C, Adams RE, et al. Evaluation of an internet support group for women with primary breast cancer. Cancer 2003;97:1164-73.

[49] Taylor S, Lobel M. Social comparison activity under threat: downward evaluation and upward contacts. Psychol Rev 1989;96:569-75.

[50] Taylor S. Adjustment to threatening events: a theory of cognitive adaptation. Am Psychol 1983;38:1161-73.

[51] Karsh BT, Hamilton Escoto K, Beasley JW, Holden RJ. Toward a theoretical approach to medical error reporting system research and design. Appl Ergon 2006;37:283-95

[52] Blumer JG, Katz E. The uses of mass communications: current perspectives on gratifications research.. Beverly Hills, CA: Sage Publications; 1974.

[53] Rozmovits L, Khu KJ, Osman S, Gentili F, Guha A, Bernstein M. Information gaps for patients requiriing craniotomy for benign brain lesions: a qualitative study. J Neurooncol 2010;96:241-7. 